\title{
MATERNAL AND PERINATAL OUTCOME OF WOMEN WITH SWINE FLU IN PREGNANCY AND POSTPARTUM
}

\author{
G. Prema Priya1 , B. Jeyamani², S. Nithya ${ }^{3}$, N. Gayathri' ${ }^{4}$ D. Vimala ${ }^{5}$
}

${ }_{1}^{1}$ Assistant Professor, Department of Obstetrics and Gynaecology, Vinayaka Missions Kirupananda Variyar Medical College and Hospital, Salem, Tamilnadu. India.

${ }^{2}$ Associate Professor, Department of Obstetrics and Gynaecology, Vinayaka Missions Kirupananda Variyar Medical College and Hospital, Salem, Tamilnadu. India.

${ }^{3}$ Assistant Professor, Department of Obstetrics and Gynaecology, Vinayaka Missions Kirupananda Variyar Medical College and Hospital, Salem, Tamilnadu. India.

${ }^{4}$ Assistant Professor, Department of Obstetrics and Gynaecology, Vinayaka Missions Kirupananda Variyar Medical College and Hospital, Salem, Tamilnadu. India.

5Professor, Department of Obstetrics and Gynaecology, Vinayaka Missions Kirupananda Variyar Medical College and Hospital, Salem, Tamilnadu. India.

\section{BACKGROUND}

ABSTRACT

Novel influenza A or swine flu causes widespread outbreak of respiratory infection worldwide. Pregnancy and postpartum has four to five-fold increased risk of complications and serious illness. The present study was undertaken to analyse the maternal and perinatal outcome of women with swine flu in pregnancy and postpartum period.

\section{METHODS}

This was a retrospective study done in a tertiary hospital in Salem district of Tamilnadu. Only confirmed cases of swine flu in pregnancy and postpartum were included in the study. The study period was October 2015 to November 2018. Patient symptoms, signs, laboratory abnormalities, criteria for ICU admission, maternal and perinatal outcome were analysed in this study.

\section{RESULTS}

A total of thirty-one women was included in the study. All were throat swab positive for H1N1 Real Time PCR. The overall maternal mortality was $9.6 \%$ and perinatal mortality was $16.6 \%$. Pneumonia, respiratory failure and coagulopathy were the causes of maternal deaths.

\section{CONCLUSIONS}

Vaccination, high index of suspicion, early diagnosis, antiviral therapy, and early referral to higher centres is mandatory in all suspected cases of swine flu in pregnant and postpartum woman to reduce both maternal and perinatal complications.

HOW TO CITE THIS ARTICLE: Priya GP, Jeyamani B, Nithya S, et al. Maternal and perinatal outcome of women with swine flu in pregnancy and postpartum. J. Evolution Med. Dent. Sci. 2019;8(18):1419-1421, DOI: 10.14260/jemds/2019/316

\section{BACKGROUND}

Novel Influenza A H1N1 or swine flu is identified as the cause for widespread outbreak of respiratory infection worldwide.[1] In 2009, WHO has declared the pandemic of swine flu. [2] Centre for disease control 2009 has reported that swine flu has caused greater disease burden in young people than old age. In 2009 pandemic, $18-25 \%$ of patients with swine flu admitted in ICU.[3] Swine flu is due to the triple reassortment of genes between avian, swine and human. Pregnancy being immunosuppressed state is at high risk of contracting swine flu and developing its complications. Swine flu has been associated with high maternal and perinatal morbidity and mortality.[4]

'Financial or Other Competing Interest': None.

Submission 15-03-2019, Peer Review 19-04-2019,

Acceptance 26-04-2019, Published 06-05-2019.

Corresponding Author:

Dr. B. Jeyamani,

Associate Professor,

Department of Obstetrics and Gynaecology,

Vinayaka Missions Kirupanandavariyar

Medical College and Hospital, Salem, Tamilnadu. India.

E-mail:drjeyamani@gmail.com dr.premapriya.r@gmail.com

DOI: $10.14260 /$ jemds $/ 2019 / 316$
Pregnant and recently delivered are at four to five-fold increased risk of complications with swine flu. [5] Pneumonia is more commonly seen in pregnant woman affected by swine flu due to reduced tidal volume and congestion of lungs.[2] Fetal hypoxia is more common in the neonates. The aim of the present study was to analyse the maternal and perinatal outcome of women with swine flu in pregnancy and postpartum.

\section{METHODS}

This was a retrospective study done over three years from October 2015 to November 2018 in a tertiary hospital in Salem district of Tamilnadu. The data were acquired retrospectively from hospital records after obtaining institute ethical committee clearance. Only confirmed throat swab Real time PCR positive cases admitted in hospital in pregnant and postpartum woman were included in the study. Other causes of respiratory disorders and clinically suspected cases of swine flu were excluded from the study. Demographic profiles of all these patients were noted along with obstetric histories. Patient symptoms such as cough, sore throat, fever, chills, myalgia, dyspnoea were taken into account. Signs such as temperature above $1000 \mathrm{~F}$, tachycardia, hypotension, crepitations, and altered sensorium were also noted. Patient vital signs on admission, laboratory reports, radiographic 
findings and criteria for ICU admission were also noted. Time interval between onset of symptoms and starting antiviral therapy was recorded. Maternal outcome such as mode of delivery, morbidity, mortality and perinatal outcome were analysed. Data were analysed using SPSS 21 and expressed in number, frequencies and percentages.

\section{RESULTS}

A total of thirty-one patients with confirmed swine flu in pregnancy and postpartum admitted in hospital over a period of three years from October 2015 to November 2018 were taken for the study. Among thirty-one patients 21 were antenatal and 10 were postnatal. The mean age of these patients were 28.4 years. Of the antenatal, primigravida constituted 15 and multigravida constituted 6. Women delivered within two weeks positive for swine flu were also included in the study. All these patients were H1N1 positive confirmed by throat swab RT-PCR. Ten patients had anaemia complicating pregnancy and one had gestational hypertension.

Patient's symptoms and signs at the time of admission were noted in Table 1 and 2. Almost all patients had fever, cough, sore throat, temperature above $100^{\circ} \mathrm{F}$ and tachycardia. Few had chills, dyspnoea and crepitations. None of the patients had nausea, vomiting, diarrhoea and altered sensorium. Laboratory abnormalities were recorded in table 3. None of the patients had history of asthma or vaccination against influenza. Almost all patients were treated with paracetamol, antibiotics and cold remedies before admission. Once swine flu confirmed, all patients were treated with oseltamivir $75 \mathrm{mg}$ twice daily for five days. The mean interval of starting oseltamivir was three and half days from symptom onset. 18 patients received the drug within 48 hours. The longest interval of starting the drug was 7 days. It was noticed in postnatal women who delivered 6 days back and was referred from primary health centre. Supportive measures such as oxygen administration, intravenous antibiotics were given to all. Of the 21 antenatal, fifteen women were in second trimester ( $<28$ weeks) and six women were in third trimester. Two women delivered and the mode of delivery was caesarean section in both. One patient was at term with fetal distress. Baby had meconium aspiration syndrome and died immediately. Mother also had respiratory failure and cardiac arrest. The other patient had caesarean for severe preeclampsia with fetal distress at 32 weeks. The baby was stillborn. The mother died on postnatal day two due to bronchopneumonia with coagulation failure.

So totally these two antenatal and one postnatal day 6 woman had pulmonary complications, admitted in ICU and required mechanical ventilation. During their stay in ICU, these three patients had haemodynamic instability and accounted for maternal death constituting 9.6\%. Known pregnancy outcome $(n=12)$ and the perinatal mortality was $(16.6 \%)$. The rest of the patients were recovered and discharged.

\begin{tabular}{|c|c|}
\hline Symptoms & N= 31 n (\%) \\
\hline Fever & $31(100 \%)$ \\
\hline Cough & $31(100 \%)$ \\
\hline Sore throat & $31(100 \%)$ \\
\hline
\end{tabular}

\begin{tabular}{|c|c|}
\hline Chills & $22(71 \%)$ \\
\hline Weakness, myalgia & $10(32 \%)$ \\
\hline Dyspnoea & $10(32 \%)$ \\
\hline Diarrhoea, vomiting & Nil \\
\hline \multicolumn{2}{|c|}{ Table 1. Symptoms } \\
\hline
\end{tabular}

\begin{tabular}{|c|c|}
\hline Signs & N=31 n (\%) \\
\hline Fever above $100^{\circ} \mathrm{F}$ & $31(100 \%)$ \\
\hline Tachycardia & $31(100 \%)$ \\
\hline Hypotension & $6(19 \%)$ \\
\hline Crepitation/ rhonchi & $5(16 \%)$ \\
\hline Altered sensorium & Nil \\
\hline \multicolumn{2}{|c|}{ Table 2. Signs } \\
\hline
\end{tabular}

\begin{tabular}{|c|c|}
\hline Laboratory Abnormalities & $\mathrm{N}=31 \mathrm{n}(\%)$ \\
\hline Anaemia & $10(32 \%)$ \\
\hline Leucocytosis & $20(64 \%)$ \\
\hline Leucopoenia & $12(38 \%)$ \\
\hline Thrombocytopenia & $1(3.2 \%)$ \\
\hline Chest $\mathrm{X}$ ray consolidation & $3(9.6 \%)$ \\
\hline Decreased oxygen saturation & $3(9.6 \%)$ \\
\hline Coagulation failure & $1(3.2 \%)$ \\
\hline \multicolumn{2}{|c|}{ Table 3. Laboratory Abnormalities } \\
\hline
\end{tabular}

\section{DISCUSSION}

Swine flu is a respiratory infection caused by H1N1. It is spread by droplet infection and the incubation period is one to four days. Children and pregnant women are at risk from severe infection. Most of them present with fever, cough, sore throat, rhinorrhoea and tachycardia. Pregnant woman are susceptible to complications and have four to five fold increase rate of serious illness. Hyperthermia in early pregnancy causes neural tube defect and congenital anomalies. Febrile illness in mother causes non reassuring fetal heart such as fetal tachycardia, preterm delivery and fetal death. The mean age of the patients in our study was 28.4 years. This was similar to Archana Mishra et al study.[6] At the time of admission 21 patients were antenatal. None of them were in first trimester. This was also similar to Archana Mishra et al study.

The maternal mortality in the present study was 9.6\%. This was less when compared to other studies done by Archana Mishra et al, Jamieson et al, Mathur et al, Siston et al and Patel et al.[6-10] The cause of death was bronchopneumonia, ARDS, respiratory and coagulation failure. The mean interval of starting oseltamivir was three and half days in the present study. This was similar to Archana Mishra et al study. Pramanick A et al study reported median time of six days in starting oseltamivir in nonsurvivor pregnant women suffering from influenza.[11]

The best way to reduce the risk of spreading infection is by prevention. Good personal hygiene includes frequent hand washing, covering nose and mouth using face masks, vaccination and avoiding crowded places when sick. Pregnant woman with swine flu should be managed by multidisciplinary approach involving obstetric unit, anaesthesia and respiratory medicine team. Treatment with antivirals such as oseltamivir and zanamivir should be 
started once swine flu is suspected clinically before awaiting test results as the sensitivity of real time PCR is only 10 to $65 \% .[12,13]$ These antiviral drugs are effective when started within 48 hours of the symptoms. The limitation of the present study was that it was a retrospective study with small sample size and those treated on outpatient basis were few in number.

\section{CONCLUSIONS}

Awareness programmes should be conducted at the community health level to increase awareness and surveillance regarding swine flu and its complications among the public, staff nurses and treating physicians. Vaccination, high index of suspicion, early diagnosis, antiviral therapy and early referral to higher centres is mandatory in all suspected cases of swine flu in pregnant and postpartum women to reduce both maternal and perinatal complications. We further recommend prospective studies in future for quantification of disease burden in these areas.

\section{REFERENCES}

[1] World Health Organisation. Pandemic (H1N1) 2009update $76 . \quad$ Available from: http://www.who.int/csr/don/2009_11_27a/en/index .html

[2] Dawood FS, Jain S, Finelli L, et al. Emergence of a novel swine-origin influenza A (H1N1) virus in humans. N Engl J Med 2009;360(25):2605-15.

[3] Centers for Disease Control and Prevention. Hospitalized patients with novel influenza A (H1N1) virus infection California, April-May 2009. MMWR Morb Mortal Wkly Rep 2009;58(19):536-41.

[4] Beigi RH, Hodges J, Baldisseri M, et al. Clinical review: considerations for the triage of maternity care during an influenza pandemic--one institution's approach. Crit Care 2010;14(3):225.

[5] Singanayagam A, Wood V, Chalmers JD, et al. Factors associated with severe illness in pandemic 2009 influenza a (H1N1) infection: implications for triage in primary and secondary care. J Infect 2011;63(4);24351.

[6] Mishra A, Sachdeva HC, Malik S, et al. Outcome of critical pregnant and postpartum patients of swine fluexperience of seven years. J Clin Diagn Res 2018;12(1):QC12-5.

[7] Jamieson DJ, Honein MA, Rasmussen SA, et al. H1N1 2009 influenza virus infection during pregnancy in the USA. Lancet 2009;374(9688):451-58.

[8] Mathur S, Dubey T, Kulshrestha M, et al. Clinical profile and mortality among novel influenza A (H1N1) infected patients: 2009-2010 Jodhpur, Rajasthan pandemic. J Assoc Physicians India 2013;61(9):62732.

[9] Siston AM, Rasmussen SA, Honein MA, et al. Pandemic 2009 influenza A (H1N1) virus illness among pregnant women in the United States. JAMA 2010;303(15):1517-25.

[10] Patel M, Dennis A, Flutter C, et al. Pandemic (H1N1) 2009 influenza. Br J Anaesth 2010;104(2):128-42.

[11] Pramanick A, Rathore S, Peter JV, et al. Pandemic (H1N1) 2009 virus infection during pregnancy in South India. Intl J Gynaecol Obstet 2011;113(1):32-5.

[12] WHO information for laboratory diagnosis of pandemic (H1N1) 2009 virus in human revised. http://www.who.int/csr/resources/publications/swi neflu/realtimeptpcr/en/index.html.

[13] http://www.who.int/csr/resources/publications/swi neflu/storage_transport/en/index.html 